\title{
Curcumin reduces the cytotoxicity and osteogenesis inhibition induced by oxidative stress via inhibited the NF-KB and MAPK signaling
}

\author{
Qihua $\mathbf{Q i}^{1,2, *}$, Liangping $\mathbf{L i}^{3, *}$, Ze min Ling ${ }^{1,2}$, Yan Chen ${ }^{1,2}$, Junxuan Ma ${ }^{2}$, Wei Guo ${ }^{1,2}$, \\ Manman Gao ${ }^{1,2}$, Zhiyu Zhou ${ }^{2}$, R. Geoff Richards ${ }^{4}$ and Xuenong Zou ${ }^{1,2}$ \\ ${ }^{1}$ Department of Spine Surgery, Orthopedic Research Institute, The First Affiliated Hospital of Sun Yat-sen University, \\ Guangzhou, 510080, China \\ ${ }^{2}$ Guangdong Provincial Key Laboratory of Orthopaedics and Traumatology, The First Affiliated Hospital of Sun Yat-sen \\ University, Guangzhou, 510080, China \\ ${ }^{3}$ Department of Orthopaedic Surgery, Sir Run Run Shaw Hospital, Medical College of Zhejiang University, Hangzhou, 310016, \\ China \\ ${ }^{4}$ AO Research Institute Davos, Davos, 7270, Switzerland \\ *These authors contributed equally to this work
}

Correspondence to: Xuenong Zou, email: zxnong@hotmail.com

Keywords: oxidative stress; osteogenesis; reactive oxygen species; curcumin; bone fusion

Received: October 30, $2017 \quad$ Accepted: December 05, $2017 \quad$ Published: January 02, 2018

Copyright: Qi et al. This is an open-access article distributed under the terms of the Creative Commons Attribution License 3.0 (CC BY 3.0), which permits unrestricted use, distribution, and reproduction in any medium, provided the original author and source are credited.

\section{ABSTRACT}

Excessive oxidative stress is considered a significant pathogenic factor leading to the failure of bony fusion at the interface between implanted materials and the host. Curcumin has demonstrated anti-inflammatory and antioxidant properties. However, there were few studies investigating the effects of curcumin on osteogenesis, as well as the underlying mechanism involved in pre-osteoblastic MC3T3-E1 cells. We established an oxidative damage model by exposing MC3T3-E1 cells to hydrogen peroxide $\left(\mathrm{H}_{2} \mathrm{O}_{2}\right)$ for $24 \mathrm{~h}$ before osteogenic induction with curcumin. We discovered that oxidative stress diminished the viability of MC3T3-E1 cells, inhibited alkaline phosphatase (ALP) activity and calcium mineralization, and down-regulated osteogenesis-related gene expression; low concentrations of curcumin (1-10 $\mu \mathrm{M})$ reversed the effects of oxidative stress during osteogenic induction, but high concentrations $(20 \mu \mathrm{M})$ did not. Notably, curcumin exerted its protective effects in part by inhibiting the phosphorylation of JNK and p38 induced by $\mathrm{H}_{2} \mathrm{O}_{2}$ and by blocking of the NF-KB signaling pathway. In vivo analysis indicated that curcumin alleviated the deterioration of the micro-architecture of trabecular bone and the reduction in bone mineral density (BMD) of the distal femur; the protective effects of curcumin were dose-dependent. Taken together, these results indicate that curcumin can exert protective effects on osteogenesis and bone remodeling via inhibition of the NF-KB and MAPK pathways. This study suggests that curcumin might be effective in preventing oxidative stress and facilitate osteogenesis.

\section{INTRODUCTION}

The clinical demands for bone repair materials are enormous in spinal fusion. To date, many kinds of bone repair materials have achieved good bony fusion in spine surgery. However, several patients still suffer intervertebral bony fusion failure, with an incidence of approximately $4-20 \%[1,2]$. Our previous studies have found that fibrosis at the interface between bone and repair materials were main pathology in the bone nonunion case of anterior lumbar interbody fusion (ALIF) porcine model $[3,4]$. Although excellent materials and advanced technology have developed rapidly, promoting bone formation and avoiding fibrosis remains a large challenge for researchers. The key regulatory mechanism controlling interactions between bone repair materials and the host during bone formation is currently unclear. To elucidate the molecular mechanisms of spinal fusion in anterior 
lumbar interbody fusion, we examined gene-expression profiles after the implantation of bone repair materials using microarray technology, and the data analysis showed that mesenchymal stem cells (MSCs) around bone repair materials primarily undergo oxidative stress, hypoxic stress and endoplasmic reticular stress in the early stages $[5,6]$. Oxidative stress modulates bone formation and the recruitment, proliferation and osteogenic differentiation of MSCs; oxidative stress might therefore be an important factor in regulating osteogenesis homeostasis.

As a critical mediator of pathophysiological responses, oxidative stress describes an imbalance between excess production of reactive oxygen species (ROS), including oxygen free radicals, and insufficient antioxidant capacity $[7,8]$. The inhibition of bone remodeling by oxidative stress has been extensively studied [9]; ROS can lead to osteoblast apoptosis, as well as a reduction in osteogenesis. Many recent studies have suggested that oxidative stress plays an important role in osteoporosis pathogenesis, in a shift from the predominant "estrogen-centric" view of osteoporosis pathogenesis; the levels of ROS were elevated, and enzymatic antioxidants, such as superoxide dismutase (SOD) and glutathione peroxidase (GSH-Px), were decreased in ovariectomized animals $[10,11]$.
Curcumin (diferuloylmethane), a phenolic antioxidant extracted from curcuma longa and turmeric, has been reported to have anti-cancer, antioxidant, and anti-inflammatory properties [12-14]. Its negligible toxicity and multiple therapeutic effects have attracted considerable attention in medicine [15]. Cytoprotective roles of curcumin have been demonstrated, including the alleviation of tissue damage stemming from lipid peroxidation, free radicals, and hypoxia [16]. Additionally, curcumin has demonstrated renal-protective effects by inhibiting oxidative stress in rhabdomyolysisinduced acute kidney injury in rats [17]. Curcumin has also demonstrated protective functions against oxidative injury during inflammation or aging-related scenarios [18]. A low dose of dietary curcumin significantly decreased inflammation in the brain in a mouse model of Alzheimer's disease [19]. Curcumin has been reported to act on multiple cellular targets and signaling pathways to suppress the production of mediators of oxidative damage.

Due to their long-standing use and minimal side effects compared to western medicine, natural product compounds incorporating antioxidant and antiinflammatory properties may be a promising and safe
A

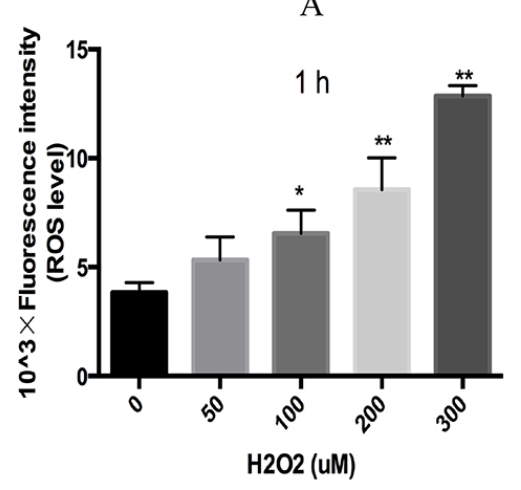

D

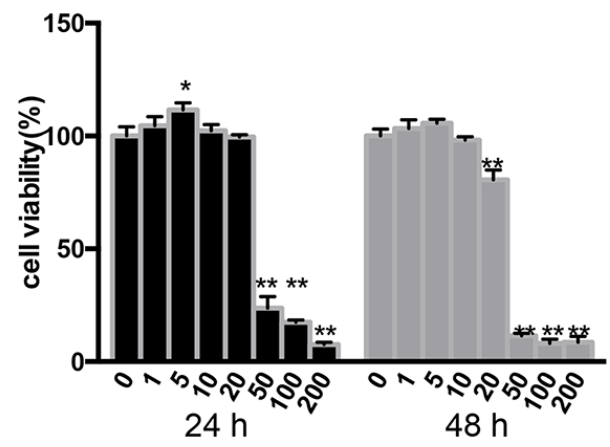

B

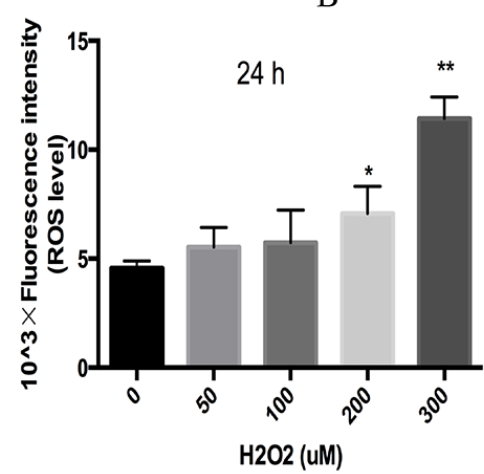

C

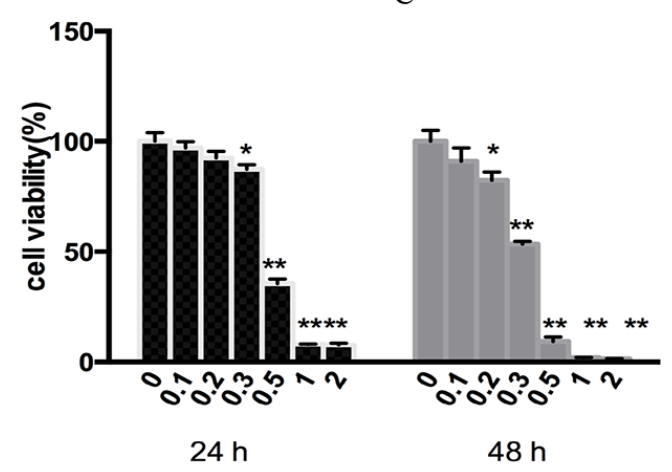

E

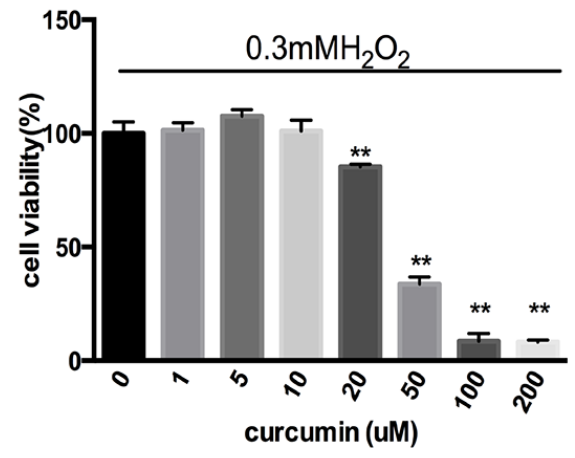

Figure 1: Levels of intracellular ROS in MC3T3-E1 cells and the cell viability under different concentrations of $\mathrm{H}_{2} \mathrm{O}_{2}$ and curcumin. (A, B) The levels of intracellular ROS at $1 \mathrm{~h}$ and $24 \mathrm{~h}$ were determined using flow cytometry after MC3T3-E1 cells were incubated with $\mathrm{H}_{2} \mathrm{O}_{2}$ at the above concentrations. (C) Effects of different concentrations of $\mathrm{H}_{2} \mathrm{O}_{2}(0.1,0.2,0.3,0.5,1$ and 2 mM) on the viability of cells cultured for $24 \mathrm{~h}$ or $48 \mathrm{~h}$. (D) The viability of cells cultured with different concentrations of curcumin $(0,1,5$, 10, $20,50,100$ and $200 \mu \mathrm{M}$ ) for $24 \mathrm{~h}$ and $48 \mathrm{~h}$. (E) The viability of cells exposed to $0.3 \mathrm{mM} \mathrm{H}_{2} \mathrm{O}_{2}$ for $24 \mathrm{~h}$ after pretreatment with different concentrations of curcumin for 24 h. Data are presented as the means \pm S.E.M. ${ }^{*} p<0.05$ and ${ }^{* * *} p<0.01$ versus control. 
solution to chronic disease [20]. The aims of the present study were to investigate the capacity of curcumin to prevent $\mathrm{H}_{2} \mathrm{O}_{2}$-induced oxidative stress and to examine the underlying mechanism. We showed that $\mathrm{H}_{2} \mathrm{O}_{2}-$ induced oxidative stress was mediated by p-P65, p-JNK, and p-P38 activation in MC3T3-E1 cells, and this effect was attenuated with curcumin treatment. In our mouse model, systemic administration of curcumin significantly improved bone mineral density and trabecular bone architecture. This explorative study provides evidence that this natural pleiotropic agent may effectively prevent oxidative stress.

\section{RESULTS}

\section{A cellular model of oxidative stress, and curcumin inhibition of $\mathrm{H}_{2} \mathrm{O}_{2}$-induced cytotoxicity}

We mimicked oxidative stress conditions after with cells exposed to $\mathrm{H}_{2} \mathrm{O}_{2}$ in vitro. We evaluated the level of oxidative stress in different conditions by measuring intracellular ROS levels with flow cytometry. Levels of intracellular ROS were increased in a dose-dependent manner after treatment with $\mathrm{H}_{2} \mathrm{O}_{2}$ for $1 \mathrm{~h}$ and $24 \mathrm{~h}$. The levels of intracellular ROS significantly increased when exposed to $0.3 \mathrm{mM} \mathrm{H}_{2} \mathrm{O}_{2}$ for $1 \mathrm{~h}$ (Figure 1A, 1B), which was slightly higher than the levels at 24h. MC3T3-E1 cell viability decreased gradually when MC3T3-E1 cells were incubated with $\mathrm{H}_{2} \mathrm{O}_{2}$ for $24 \mathrm{~h}$ at concentrations over $0.3 \mathrm{mM}$ and for $48 \mathrm{~h}$ at concentrations over $0.2 \mathrm{mM}$ (Figure 1C). Co-culture with curcumin alone at concentrations of $20 \mu \mathrm{M}$ or lower for $24 \mathrm{~h}$ did not affect cell viability, but the viability decreased at a concentration of $20 \mu \mathrm{M}$ at $48 \mathrm{~h}$ (Figure 1D). Importantly, $10 \mu \mathrm{M}$ or lower curcumin pretreatment in cells exposed to $0.3 \mathrm{mM}$ $\mathrm{H}_{2} \mathrm{O}_{2}$ rescued cell viability, but this effect was not seen at the $20 \mu \mathrm{m}$ curcumin concentration (Figure 1E). This result indicates that curcumin can partially protect $\mathrm{H}_{2} \mathrm{O}_{2}$-induced cytotoxicity below $10 \mu \mathrm{M}$.

\section{Inhibition of osteogenic differentiation by $\mathrm{H}_{2} \mathrm{O}_{2}$ is reversed by curcumin treatment in vitro}

ALP activity is considered an early indicator for osteogenesis, ALP activity and staining were measured at 7 days, and calcium levels were measured at 21 days. The ALP activity decreased gradually when the concentration of $\mathrm{H}_{2} \mathrm{O}_{2}$ was greater than $0.1 \mathrm{mM}$, and the calcium level decreased markedly when the concentration was over $0.3 \mathrm{mM}$. Our experiments focused on the osteogenesis of the cells, so we selected $0.3 \mathrm{mM}$ for this trial. The ALP activity and the calcium level in the cells decreased markedly when co-cultured with $20 \mu \mathrm{M}$ curcumin alone and we therefore choose $20 \mu \mathrm{M}$ as the critical curcumin concentration used to determine the curcumin protective effects, For the overall cellular osteogenic effects, we chose the representative concentrations of $1,10,20 \mu \mathrm{M}$ curcumin in the experiments (Figure 2A, 2B).

The osteogenic medium containing different concentrations of curcumin were added after the cells were exposed to $\mathrm{H}_{2} \mathrm{O}_{2}$ for $24 \mathrm{~h}$. Co-treatment of 1 and $10 \mu \mathrm{M}$ curcumin reversed $\mathrm{H}_{2} \mathrm{O}_{2}$-induced dysfunction, as demonstrated by increased ALP staining, activity and calcium level, but $20 \mu \mathrm{M}$ curcumin did not reverse the $\mathrm{H}_{2} \mathrm{O}_{2}$ effect (Figure 2C-2F). $10 \mu \mathrm{M}$ curcumin treatment reversed $\mathrm{H}_{2} \mathrm{O}_{2}$-induced calcium level dysfunction markedly, and $1 \mu \mathrm{M}$ treatment reversed the ALP activity dramatically.

\section{Curcumin reversed the effects of oxidative stress on the expression of osteogenesis-related genes}

We further investigated the effects of different concentrations $(1,10,20 \mu \mathrm{M})$ of curcumin on the expression of osteogenic genes, including alp, colla1, runx 2 and opn, using RT-PCR. The expression of these markers decreased dramatically in the $\mathrm{H}_{2} \mathrm{O}_{2}$-treated group. The expression levels of three osteogenic genes, alp, runx2 and collagen 1, were significantly upregulated with $1 \mu \mathrm{M}$ curcumin treatment after exposure to 0.3 $\mathrm{mM} \mathrm{H}_{2} \mathrm{O}_{2}$, and the expression of opn was up-regulated in all groups compared with the $\mathrm{H}_{2} \mathrm{O}_{2}$ group (Figure $3 \mathrm{~A}-3 \mathrm{D})$. All of the genes except for opn decreased with $20 \mu \mathrm{M}$ curcumin treatment. Therefore, the above results suggest that 1 and $10 \mu \mathrm{M}$ curcumin treatment partially protected the inhibition of osteogenic differentiation by oxidative stress through the promotion of osteogenic gene expression.

\section{Expression of RANKL and IL-6 was inhibited by curcumin}

Osteoblasts interact with osteoclasts synergistically to regulate the metabolism of bone tissue. The osteoblasts always secrete several cytokines, which affect the activity of the osteoclasts in bone remodeling. RANKL and IL-6 are considered two important factors secreted by osteoblasts. After exposure to $0.3 \mathrm{mM} \mathrm{H}_{2} \mathrm{O}_{2}$ for $24 \mathrm{~h}$, the expression levels of RANKL and IL-6 increased over 7 days of osteogenic induction. However, when cells were co-cultured with curcumin, the elevated expression of RANKL and IL-6 was partially inhibited, especially at the $1 \mu \mathrm{M}$ and $10 \mu \mathrm{M}$ curcumin (Figure 4A, 4B).

\section{Curcumin reduced the production of reactive oxygen species triggered by $\mathrm{H}_{2} \mathrm{O}_{2}$ in MC3T3-E1 cells}

We have observed that the production of ROS significantly increased when cells were exposed to $\mathrm{H}_{2} \mathrm{O}_{2}$. The production of ROS increased with increasing concentrations of $\mathrm{H}_{2} \mathrm{O}_{2}$, and the ROS come to the highest 
level when cells were treated with $0.3 \mathrm{mM} \mathrm{H}_{2} \mathrm{O}_{2}$ for $1 \mathrm{~h}$. ROS production was partially suppressed by pretreatment with different concentrations $(1,10,20 \mu \mathrm{M})$ curcumin for $24 \mathrm{~h}$. As shown in the representative photographs of DCF fluorescence, as well as in the relative DCF quantification (Figure 5A, 5B), $20 \mu \mathrm{M}$ curcumin markedly reduced intracellular ROS levels induced by $\mathrm{H}_{2} \mathrm{O}_{2}$.

\section{$\mathrm{NF}-\kappa \mathrm{B}$ and MAPK pathways are involved in the anti-oxidative stress effects of curcumin in MC3T3-E1 cells}

As a nuclear transcription factor, NF- $\kappa \mathrm{B}$ plays a key role in regulating the expression of genes involved in osteogenesis. The expression of the phosphorylated p65 subunit was increased when the cells were exposed to $\mathrm{H}_{2} \mathrm{O}_{2}$. Meanwhile, I $\kappa \mathrm{B}-\alpha$, which is bound to the p65 subunit in the cytoplasm, was diminished in the $\mathrm{H}_{2} \mathrm{O}_{2}$ treated groups. In contrast, curcumin $(1 \mu \mathrm{M})$ treatment reduced the expression of p-P65 obviously but the 10 , $20 \mu \mathrm{M}$ failed, conversely, the level of I $\kappa \mathrm{B}-\alpha$ in accordance with the expression of p-P65. Therefore, curcuminmediated protection of cells from oxidative stress in osteogenesis, might occur via the inhibition of the NF- $\kappa \mathrm{B}$ signaling pathway (Figure 6A-6C). It has been previously reported that MAPK pathways, including ERK1/2, P38 and $\mathrm{JNK}$, are involved in osteogenesis. To elucidate whether curcumin reversed oxidative stress through the regulation of MAPK signaling pathways, we pre-treated MC3T3-E1 cells for $24 \mathrm{~h}$ and then cultured the cells with $\mathrm{H}_{2} \mathrm{O}_{2}$ for $1 \mathrm{~h}$. Western blot analysis showed that the levels of p-P38 and p-JNK increased and the p-ERK1/2 levels decreased with exposure to $\mathrm{H}_{2} \mathrm{O}_{2}$; curcumin partially inhibited P38 and JNK phosphorylation, with marked suppression at $20 \mu \mathrm{M}, 1 \mu \mathrm{M}$ respectively, the $10 \mu \mathrm{M}$ concentration had impact on the levels of p-P38 and p-JNK as well. curcumin had opposite effects on ERK1/2 levels (Figure 6D-6G). Here, the data indicated that the $\mathrm{H}_{2} \mathrm{O}_{2}$ mediated decrease in the osteogenesis of the MC3T3-E1 cells might be associated with the MAPK pathway. Although the most significant suppression of transcription factor with different concentrations of curcumin, curcumin exerted protection might via inhibition of $\mathrm{NF}-\kappa \mathrm{B}$ and MAPK signaling pathway.

\section{Curcumin in vivo inhibited oxidative stress}

Oxidative stress is considered the main pathological mechanism in the ovariectomy (OVX) mouse model, so we used this ovariectomized mouse model to mimic

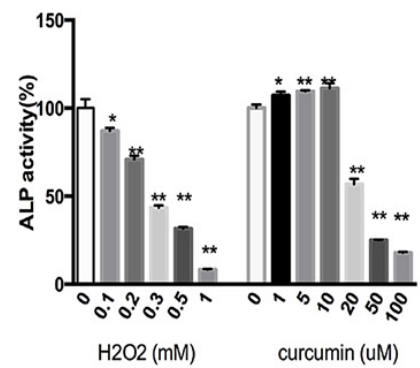

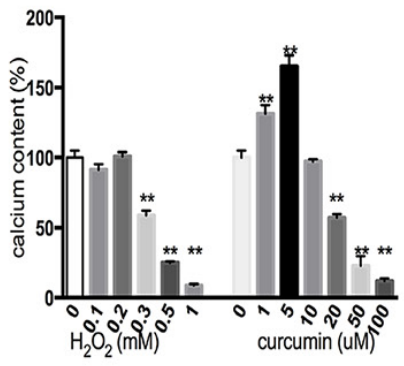

$\mathrm{C}$

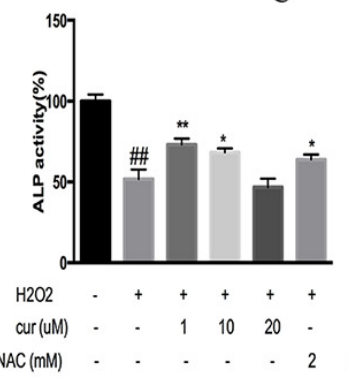

$\mathrm{D}$

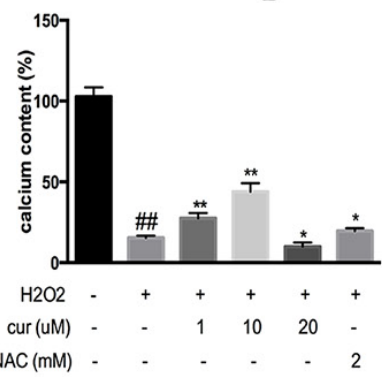

$\mathrm{E}$
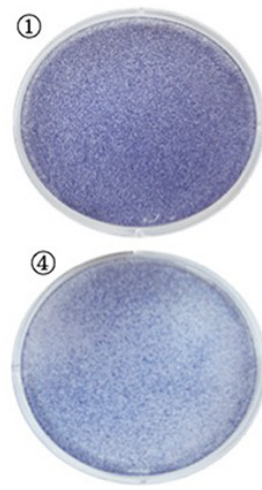
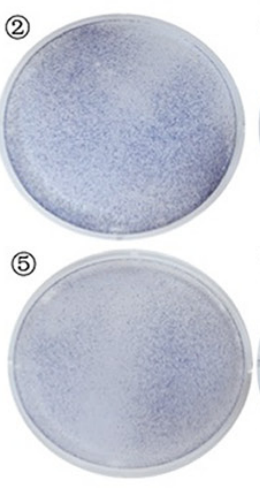
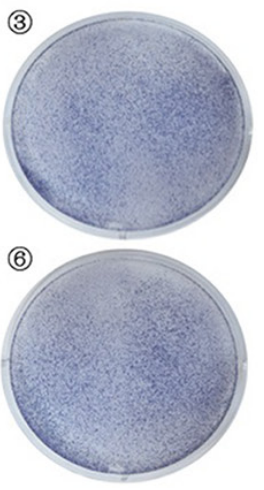
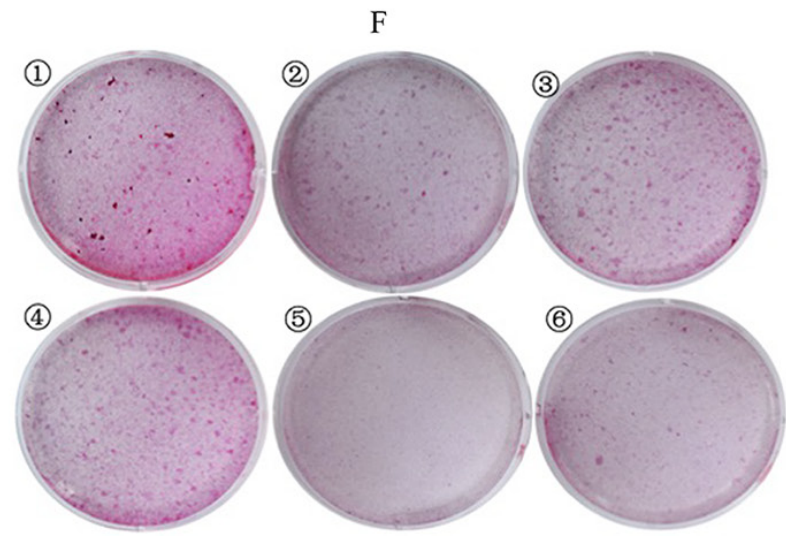

Figure 2: Curcumin protected osteogenesis inhibition from $\mathrm{H}_{2} \mathrm{O}_{2}$ treatment in MC3T3-E1 cells. (A and B) ALP activity and the calcium level with different concentrations of $\mathrm{H}_{2} \mathrm{O}_{2}$ or curcumin treatment, respectively, ${ }^{*} p<0.05$ and ${ }^{* *} p<0.01$ compared to the control group. (C and D) Protective effects of curcumin on ALP activity and calcium level in MC3T3-E1 cells after $\mathrm{H}_{2} \mathrm{O}_{2}$ treatment for 24 h. (E and F) ALP and Alizarin Red S staining indicated that curcumin protected cellular osteogenic differentiation after $\mathrm{H}_{2} \mathrm{O}_{2}$ exposure. (1): Control group; (2): $\mathrm{H}_{2} \mathrm{O}_{2}$; (3): $\mathrm{H}_{2} \mathrm{O}_{2}+\operatorname{curcumin}(1 \mu \mathrm{M})$; (4): $\mathrm{H}_{2} \mathrm{O}_{2}+\operatorname{curcumin}(10 \mu \mathrm{M})$; (5): $\mathrm{H}_{2} \mathrm{O}_{2}+\operatorname{curcumin}(20 \mu \mathrm{M})$; (6): $\mathrm{H}_{2} \mathrm{O}_{2}+\mathrm{NAC}(2 \mathrm{mM})$. $\# \# p<0.01$ compared to the control group; ${ }^{*} p<0.05$ and ${ }^{* *} p<0.01$ compared to the $\mathrm{H}_{2} \mathrm{O}_{2}$ group. 
oxidative stress conditions in vivo. Serum malondialdehyde (MDA) and glutathione (GSH) levels were evaluated in ovariectomized mice with or without curcumin intervention. The results showed that the activity of MDA in serum increased in the ovariectomized group, whereas the GSH activity decreased compared to the control group. However, the serum activities of MDA and GSH were partially rescued by curcumin treatment (Figure 7A, 7B).

\section{Curcumin improved bone mass and bone structure in ovariectomized mice}

To further study the effects of curcumin treatment on trabecular bone mass and micro-architecture, different amounts of curcumin were delivered to the ovariectomized (OVX) mice intraperitoneally, and the trabecular bone mass and micro-architecture were

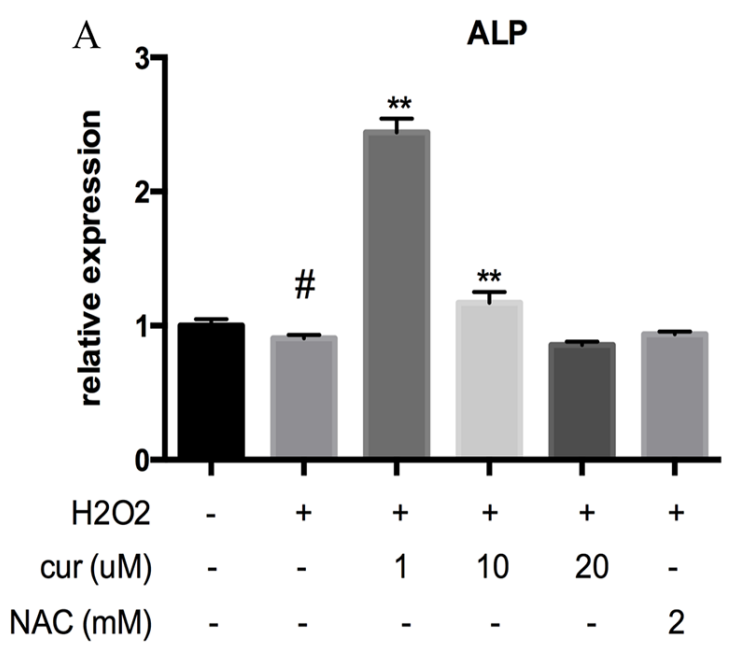

C

Runx2

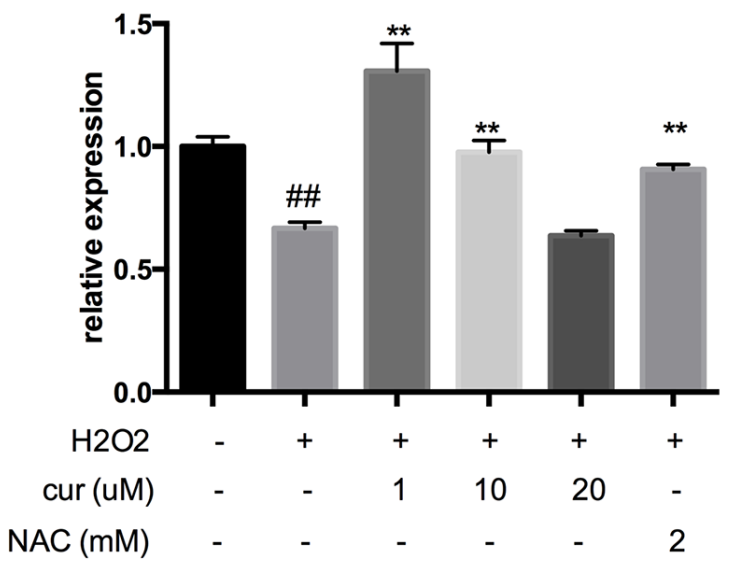

evaluated with VG (Van Gieson) staining and microcomputed tomography (micro-CT) examination in all groups. As shown in (Figure 8A), control mice showed normal compact trabeculae in the femoral condyle, but sparse, thinned trabeculae were shown in OVX mice by VG staining. The disappearance and sparse trabeculae resulted in large spaces in the condyle. Curcumin treatment $(5 \mu \mathrm{mol} / \mathrm{kg}, 15 \mu \mathrm{mol} / \mathrm{kg})$ increased the thickness, density and the quantity of trabeculae. The bone mineral density and bone mass were evaluated by micro-CT examination (Figure $8 \mathrm{~B}$ ). Bone mass and bone trabeculae deteriorated in the ovariectomized mice, as measured through decreases in BMD, Tb.N, Tb.Th and $\mathrm{BV} / \mathrm{TV}$ (Figure $8 \mathrm{C}-8 \mathrm{~F}$ ), but showed increases in BS/ TV,Tb.Sp and Tb.Pf (Figure 8G-8I). Curcumin treatment increased the bone micro-architecture and bone mineral density in a dose-dependent manner. These results

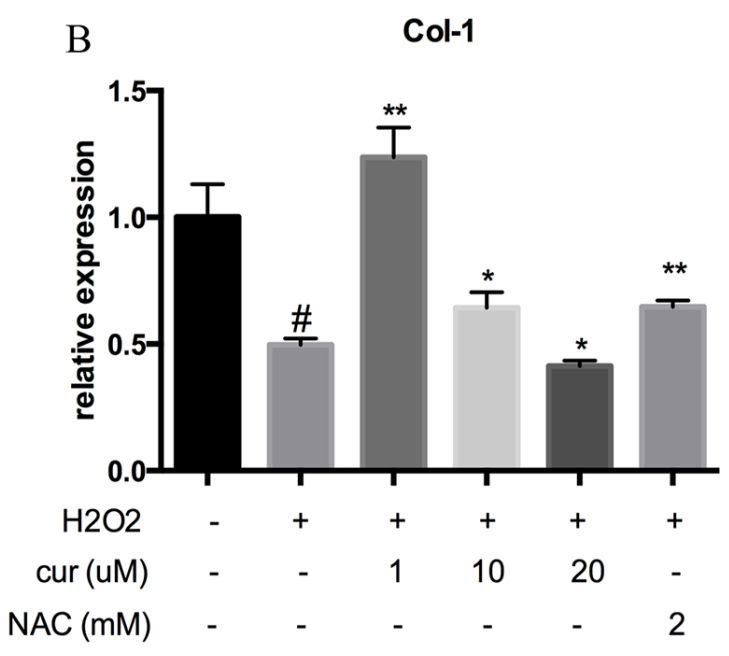

$\mathrm{D}$

Opn

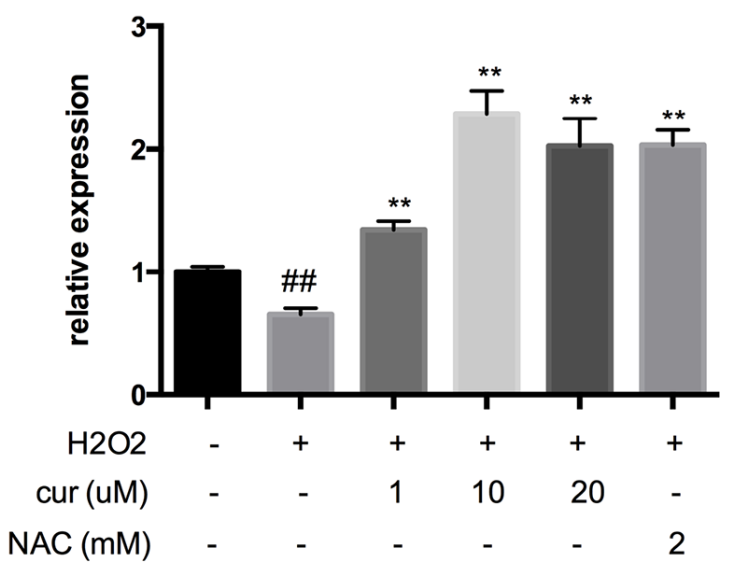

Figure 3: Protection by curcumin on the mRNA expression of alp, col1a1, runx2 and opn after exposure to $\mathrm{H}_{2} \mathrm{O}_{2}$ for 24 h. MC3T3-E1 cells were induced for 7 days with different concentrations of curcumin. (A, B) Relative Alp, Collagen I mRNA expression $(\mathbf{C}, \mathbf{D})$ Relative Runx2 and Opn mRNA expression. Gene expression was normalized to GAPDH. ${ }^{\#} P<0.05$ and ${ }^{\#} P<0.01$ compared to control group; ${ }^{*} \mathrm{P}<0.05$ and ${ }^{* *} \mathrm{P}<0.01$ compared to the $\mathrm{H}_{2} \mathrm{O}_{2}$ group. 
confirmed that curcumin is able to reverse the in vivo bone formation reduction induced by oxidative stress.

\section{DISCUSSION}

Many different types of materials, such as metals, ceramics, and polymers, have been used in total hip replacements and spinal interbody fusion. Implanted materials can induce significant oxidative stress and inflammation around materials during their degradation, and material properties, such as their composition and their surface properties, also induced oxidative stress [21, 22]. ROS are considered the main type of cellular oxidant; many studies have indicated that increased oxidative stress is involved in the pathogenesis of bone metabolism [23], and the balance between oxidants and antioxidants may determine the fate of the implant materials. Reducing the production of ROS by using antioxidant drugs would be beneficial for osteogenesis. We chose curcumin, which has excellent antioxidant properties, as a candidate for
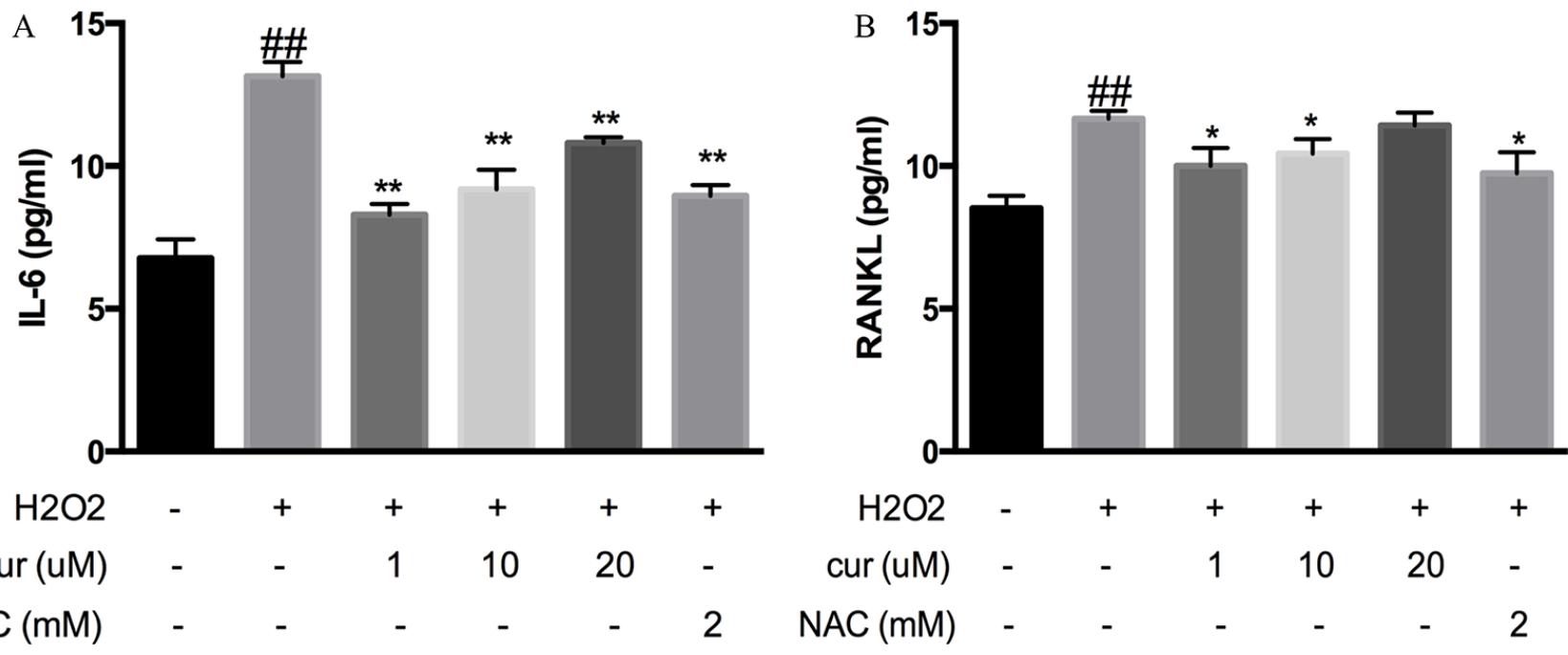

Figure 4: Curcumin down-regulated the expression of IL-6 and RANKL. After exposure to $\mathrm{H}_{2} \mathrm{O}_{2}$ for $24 \mathrm{~h}, \mathrm{MC}_{3} \mathrm{~T} 3-\mathrm{E} 1 \mathrm{cells}$ were induced for 7 days with different concentrations of curcumin. (A) The relative expression of RANKL in the presence of curcumin and/ or $\mathrm{H}_{2} \mathrm{O}_{2}$. (B) The relative expression of IL-6 in the presence of curcumin and/or $\mathrm{H}_{2} \mathrm{O}_{2}{ }^{*}{ }^{\#} P<0.01$ compared to the control group; ${ }^{*} P<0.05$ and ${ }^{* *} P<0.01$ compared to the $\mathrm{H}_{2} \mathrm{O}_{2}$ alone treatment group.

A
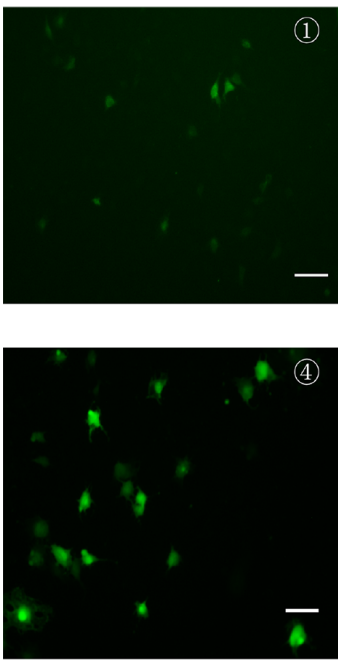
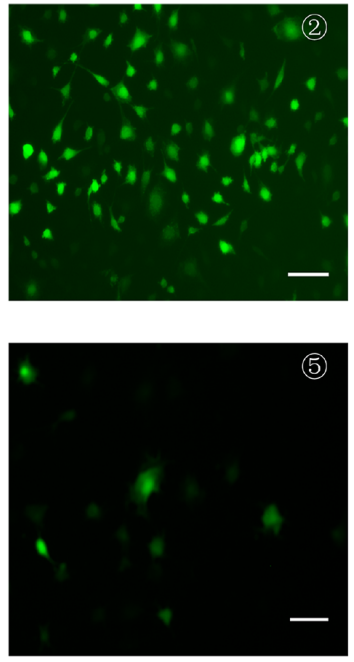
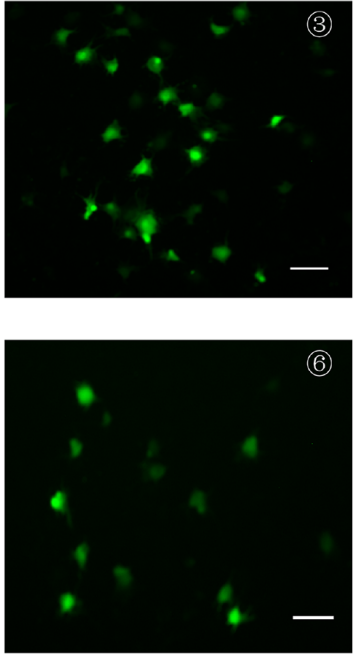

B

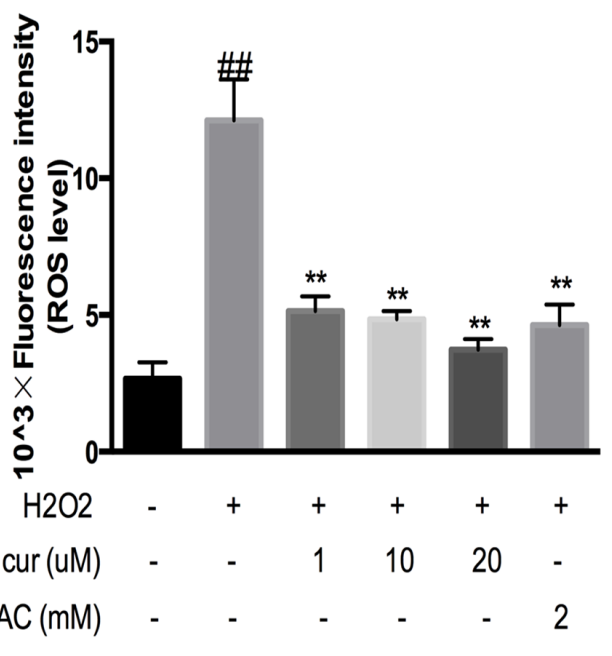

Figure 5: Curcumin reduced $\mathrm{H}_{2} \mathrm{O}_{2}$-induced intracellular ROS expression as determined by DCF fluorescence. MC3T3-E1 cells pre-treated with different concentration of curcumin prior to exposure to $\mathrm{H}_{2} \mathrm{O}_{2}$ for $1 \mathrm{~h}$. (A) Representative photographs of ROS detection by the fluorescent probe DCFH-DA, Scale bar $=20 \mu \mathrm{m}$. (B) Relative DCF fluorescence was quantified relative to the control group. (1): Control group; (2): $\mathrm{H}_{2} \mathrm{O}_{2}$; (3): $\mathrm{H}_{2} \mathrm{O}_{2}+$ curcumin $(1 \mu \mathrm{M})$; (4): $\mathrm{H}_{2} \mathrm{O}_{2}+$ curcumin $(10 \mu \mathrm{M})$; (5): $\mathrm{H}_{2} \mathrm{O}_{2}+$ curcumin (20 $\mu \mathrm{M}$; (6): $\mathrm{H}_{2} \mathrm{O}_{2}+\mathrm{NAC}(2 \mathrm{mM})$. Data are shown as the means \pm S.E.M. ${ }^{\#} p<0.01$ versus control, ${ }^{*} p<0.05$ and ${ }^{* *} p<0.01$ versus the $\mathrm{H}_{2} \mathrm{O}_{2}$-treated group. 
Table 1: Primer sequences of genes

\begin{tabular}{lll}
\hline Gene symbol & Forward primer & Reverse primer \\
\hline ALP & TGGAAGGAGGCAGGATTGA & ATCAGCAGTAACCACAGTCA \\
COL1A1 & CCTGGCAAAGACGGACTCA & GGGCTGCGGATGTTCTCAAT \\
RUNX2 & AATGCCTCCGCTGTTATGA & TTGTGAAGACTGTTATGGTCAAG \\
OPN & GTACCCTGATGCTACAGACG & TTCATAACTGTCCTTCCCAC \\
GAPDH & CTTGGGCTACACTGAGGACC & CATACCAGGAAATGAGCTTGAC \\
\hline
\end{tabular}

protection during interactions between implanted material and the host. Many studies have used hydrogen peroxide as an oxidant to mimic oxidative stress in vitro, due to its good stability and ability to pass through cell membranes, and our study re-confirmed this with flow cytometry. Different concentrations of $\mathrm{H}_{2} \mathrm{O}_{2}$, such as 80, 200, and $300 \mu \mathrm{M}$, have been used to produce oxidative stress, which may be due to the different cells included in various experiments [24-26]. And, we used $0.3 \mathrm{mM} \mathrm{H}_{2} \mathrm{O}_{2}$ to generate an oxidative stress model. Our data showed that the pre-osteoblast MC3T3-E1 cells underwent necrosis when exposed to high concentrations of $\mathrm{H}_{2} \mathrm{O}_{2}$ or curcumin, curcumin treatment (1-10 $\mu \mathrm{M})$ not only reversed the $\mathrm{H}_{2} \mathrm{O}_{2}$ toxicity but also independently promoted the viability of the cells. This study demonstrated that curcumin partially decreased $\mathrm{H}_{2} \mathrm{O}_{2}$-induced cytotoxicity in MC3T3-E1 cells. These results are consistent with previous studies [27, 28].

Our previous study indicated that oxidative stress regulated the proliferation and osteogenic differentiation of MSCs through the miR-424/FGF2 pathway [26]. Many studies have reported that oxidative stress inhibited differentiation of osteoblast-related cells, leading to reduce bone formation $[29,30]$. Exogenous addition of $\mathrm{H}_{2} \mathrm{O}_{2}$ to human BM-MSCs reduced ALP activity and abolished osteogenesis in osteoblast progenitors [31, 32]. Our experiments found that $\mathrm{H}_{2} \mathrm{O}_{2}$ exposure reduced cellular ALP activity, calcium mineralization and expression of osteogenesis-related genes, including Alp, Colla1,
A

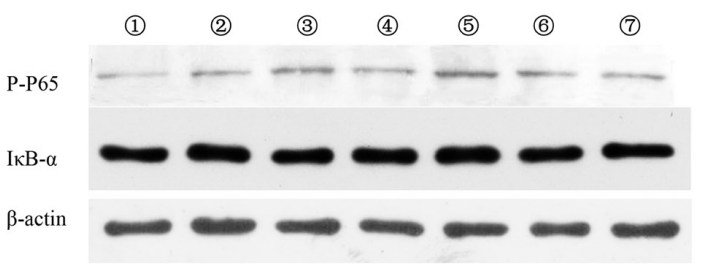

$\mathrm{D}$ (1) (2) (3) (4) (5) (6)

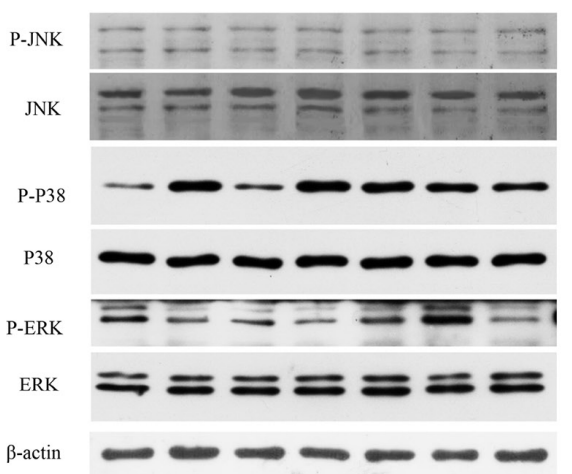

B

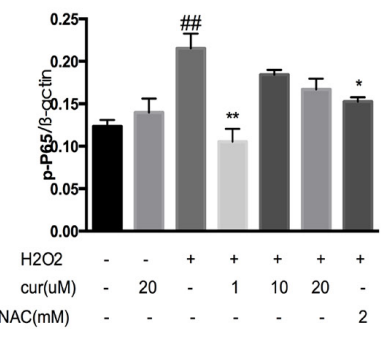

$\mathrm{E}$
C

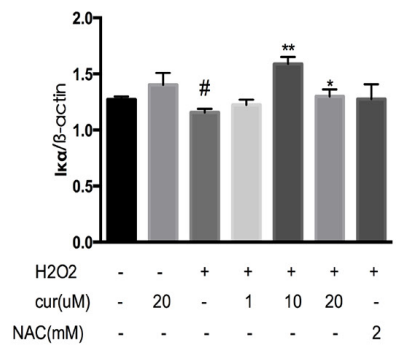

F

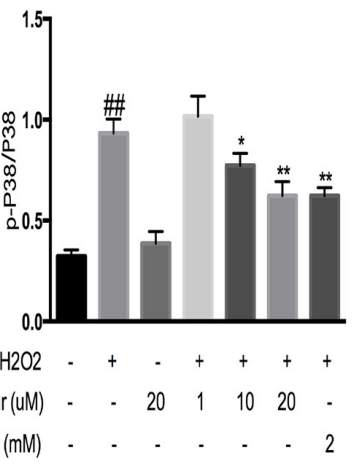

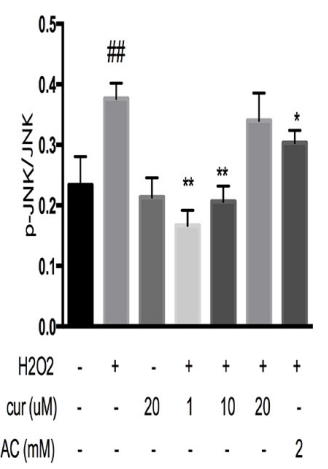

Figure 6: Both NF-кB and MAPK pathways are involved in the curcumin-mediated protection against $\mathrm{H}_{2} \mathrm{O}_{2}$ treatment. $6 \mathrm{~A}, 6 \mathrm{~B}, 6 \mathrm{C}$ Western blot analysis and relative protein expression ofp-p65 and $\mathrm{I} \kappa \mathrm{B}-\alpha$ in each group. (1): control group; (2): $\mathrm{C} 20$; (3): $\mathrm{H}_{2} \mathrm{O}_{2}$; (4): $\mathrm{H}_{2} \mathrm{O}_{2}+$ curcumin $(1 \mu \mathrm{M})$; (5): $\mathrm{H}_{2} \mathrm{O}_{2}+$ curcumin $(10 \mu \mathrm{M})$; (6): $\mathrm{H}_{2} \mathrm{O}_{2}+$ curcumin $(20 \mu \mathrm{M})$; (7): $\mathrm{H}_{2} \mathrm{O}_{2}+\mathrm{NAC}(2 \mathrm{mM})$. 6D, 6E, 6F and 6G Western blot analysis and relative protein expression levels of the MAPK pathway-related regulators p-JNK, p-ERK1/2, and p-P38 in each group.(1): control group; (2): $\mathrm{H}_{2} \mathrm{O}_{2}$; (3): $\mathrm{C} 20$ (4): $\mathrm{H}_{2} \mathrm{O}_{2}+\operatorname{curcumin}(1 \mu \mathrm{M})$; (5): $\mathrm{H}_{2} \mathrm{O}_{2}+\operatorname{curcumin}(10 \mu \mathrm{M})$; (6): $\mathrm{H}_{2} \mathrm{O}_{2}+\operatorname{curcumin}(20 \mu \mathrm{M})$; (7): $\mathrm{H}_{2} \mathrm{O}_{2}+\mathrm{NAC}(2$ $\mathrm{mM}$ ). Data are shown as the means \pm S.E.M. ${ }^{*} p<0.05$ and ${ }^{\# \#} p<0.01$ versus control group, ${ }^{*} p<0.05$ and ${ }^{* *} p<0.01$ versus $\mathrm{H}_{2} \mathrm{O}_{2}$-treatment group. 
Runx2 and Opn. Higher concentrations of curcumin also impaired ALP activity and mineralization, which was consistent with the above results. Moreover, our study showed that curcumin could reverse the $\mathrm{H}_{2} \mathrm{O}_{2}$-induced inhibition of osteogenic differentiation, and curcumin alone could enhance ALP activity and calcium levels in MC3T3-E1 cells at low concentrations. We found that 10 $\mu \mathrm{M}$ curcumin had the most obvious effect on improving osteoblastic differentiation in the face of oxidative damage, although the concentration was different from other studies, which may be due to the different cells involved and different experimental conditions [33]. Osteoblasts and osteoclasts are responsible for bone remodeling. RANKL is critical for the maturation and activity of osteoclasts, and IL-6 impaired bone formation via the dysfunction of osteoblasts. IL- 6 could affect the expression of RANKL, leading to osteoclast development. Several studies have reported that ROS could increase the expression of RANKL and IL-6 in osteoblasts [34, 35]. We observed that curcumin could reverse the effects of $\mathrm{H}_{2} \mathrm{O}_{2}$ on the production of RANKL and IL-6, which may facilitate osteogenesis.

Our study showed that curcumin treatment reduced the $\mathrm{H}_{2} \mathrm{O}_{2}$-induced production of reactive oxygen species and partially reversed the inhibition of osteogenesis. However, the molecular mechanism of the curcumin effects in the MC3T3-E1 cells has not been established. To clarify the involved mechanism, we pre-treated the cells with curcumin for $24 \mathrm{~h}$ and then co-cultured them with $\mathrm{H}_{2} \mathrm{O}_{2}$ for $1 \mathrm{~h}$. Our study demonstrated that the production of ROS was increased to a greater extent with $1 \mathrm{~h}$ co-culture. Phospho-p65, p-P38, and p-JNK were constitutively active in $\mathrm{H}_{2} \mathrm{O}_{2}$-stimulated MC3T3-E1 cells; curcumin reduced the p-P65 expression and inhibited the phosphorylation of I $\mathrm{B}-\alpha$, indicating that cells exposed to $\mathrm{H}_{2} \mathrm{O}_{2}$ activated the NF- $\kappa \mathrm{B}$ signaling pathway, which could be partially inhibited by curcumin. The concentration of $1 \mu \mathrm{M}$ curcumin exerted the greatest inhibitory effect in our experiments. Consistent with our results, curcumin has been shown to inhibit the activation of NF- $\kappa B$ [36, 37]. Bharat et al. reported that curcumin reduced the activation of NF- $\kappa \mathrm{B}$ and $\mathrm{I} \kappa \mathrm{B} \alpha$ kinase in human multiple myeloma cells [38]. In addition, curcumin alleviated oxidative stress in MC3T3-E1 cells by inhibiting P38 and JNK phosphorylation, and $20 \mu \mathrm{M}, 1 \mu \mathrm{M}$ curcumin treatment demonstrated the greatest inhibitory effect respectively, the p-JNK, p-P65 other than p-P38 are the main signaling involved in accordance with the results of osteogenesis. In agreement with our study, curcumin inhibited oxLDLtriggered foam-cell formation through the p38 and JNK pathways [39-41]. It has been reported that curcumin prevented diabetic cardiomyopathy by inhibiting the MAPK pathway in diabetic rats [42]. Taken together, these findings indicated that curcumin might decrease oxidative damage by inhibiting $\mathrm{NF}-\kappa \mathrm{B}$ and MAPK signaling activity.

Many studies have shown that oxidative damage is the main culprit to bone loss in ovariectomized mice, which is considered the classic animal model mimicking the bone metabolism of postmenopausal osteoporosis $[11,43,44]$. We therefore chose this animal model to in vivo investigate the pharmacological impact of curcumin on oxidative damage. Several studies have found that the production of MDA and GSH increases in the serum of postmenopausal women [45, 46]. Malondialdehyde (MDA) is a product of lipid peroxidation by reactive
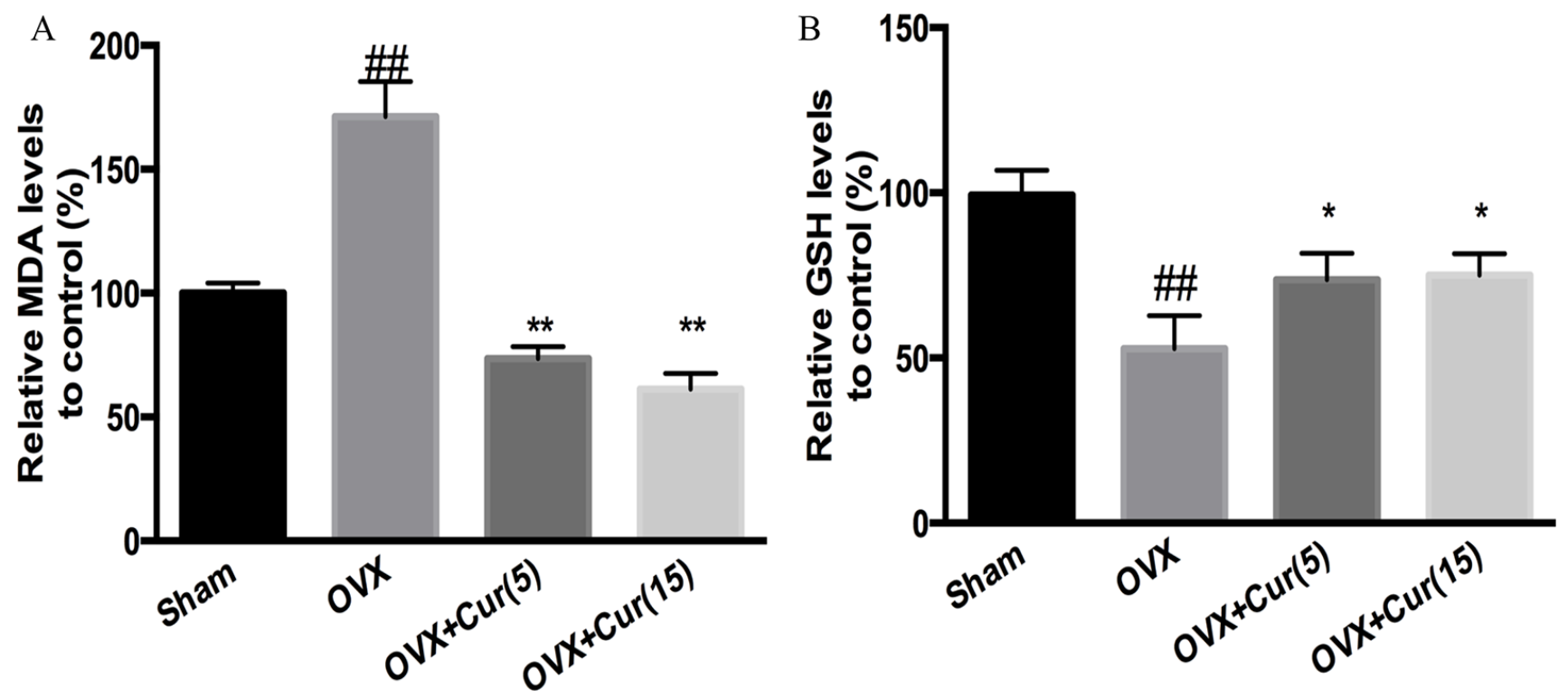

Figure 7: Curcumin attenuates oxidative stress in ovariectomized mice. (A) Serum MDA concentrations in sham operation and OVX-operation groups treated with or without curcumin. (B) Serum GSH concentrations in sham and OVX-operation groups treated with or without curcumin. \#\#P $<0.01$ compared to the sham group; ${ }^{*} P<0.05$ and ${ }^{* *} P<0.01$ compared to the OVX group. 
oxygen species; in contrast, glutathione (GSH), which removes free radicals, peroxides and toxins, is regarded as an intracellular antioxidant $[47,48]$. We found that the activity of MDA increased and the activity of GSH decreased in the oxidative damage animal model, and curcumin treatment could effectively reverse these effects.

Similarly, the oxidative damage animal model also suffers significant bone loss, as shown by the micro-architecture of the trabecular bone; this has been termed "estrogen-deficient osteogenesis" [49-51]. The micro-architecture of the trabecular bone was found to dramatically deteriorate with oxidative damage by both micro-CT scanning and VG staining. However, this process could be effectively reversed with curcumin treatment, and this protective effect was dose-dependent. Another study showed that curcumin does not have acute toxicity at daily doses of $2 \mathrm{~g} / \mathrm{kg}$ of body weight in mice and $8,000 \mathrm{mg} /$ day in humans for 3 months [52]. These results further suggest that curcumin could ameliorate

A
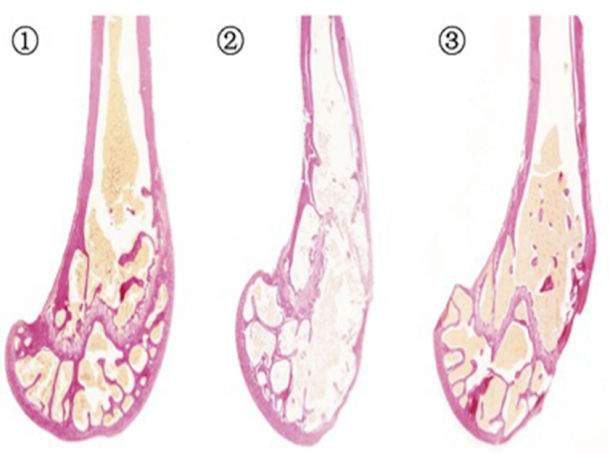

C

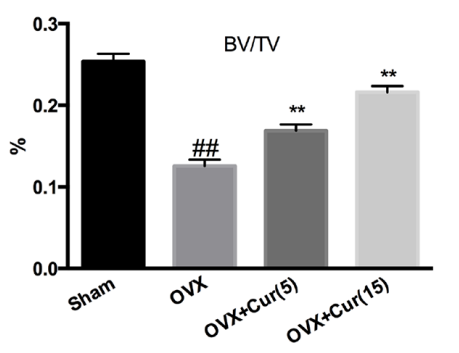

G

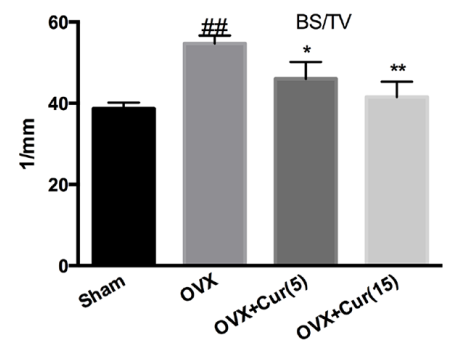

trabecular micro-architecture and bone mass deficiencies resulting from oxidative damage.

One of the limitations of the study is that although we investigated the mechanism involved in the protection of curcumin on the oxidative stress, we did not confirm the mechanism with signaling pathway inhibitor accordingly. The variation tendency of the key regulated factor of the pathway was target we focused on. Another limitation is that the ovariectomized mice were recruited to investigate the in vivo effect of the curcumin against the oxidative stress, and no materials were implanted in the animal model, because we thought the animal model could actually mimic the materials implanted environment. This study is our preliminary research, we intend to further verify our findings using an animal model with implantation of bone repair materials in the future study.

In conclusion, our studies indicate that oxidative stress due to $\mathrm{H}_{2} \mathrm{O}_{2}$ treatment in vitro resulted in cytotoxicity and inhibited the osteogenic differentiation

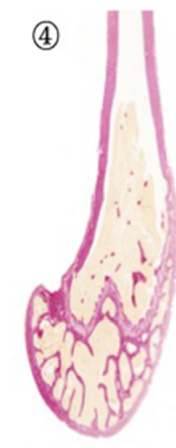

$\mathrm{D}$
$\mathrm{B}$

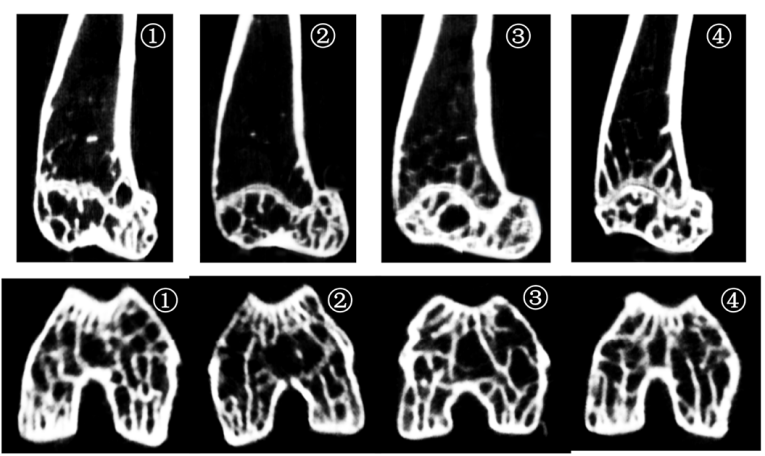

E

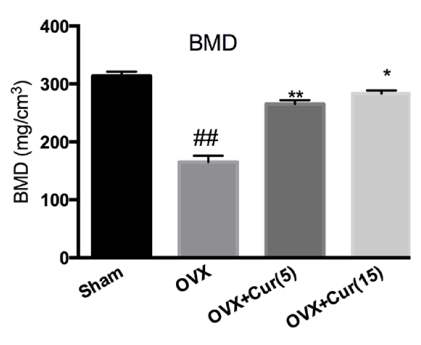

$\mathrm{H}$

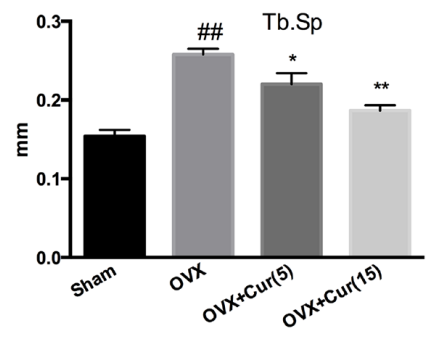

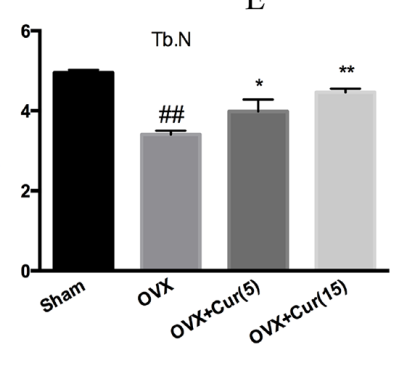

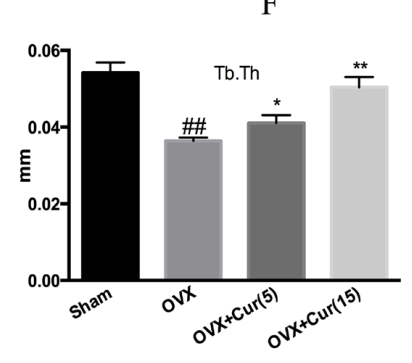

I

Figure 8: Effects of curcumin on the bone mass and micro-architecture of trabecular bone in oxidative stress animal model. (A) Van Gieson (VG) staining of the trabecular architecture of femoral condyles(100× magnification). (B) Representative microCT image of the distal metaphyseal femur region. (C-I) The following indices in the defined region of interest (ROI) in the condyle were analyzed: BV/TV,BMD, Tb.N, Tb.Th, BS/TV, Tb.Sp and Tb.Pf (1): sham group; (2): OVX; (3): OVX+curcumin ( $5 \mu \mathrm{mol} / \mathrm{kg})$; (4): OVX+curcumin $(15 \mu \mathrm{mol} / \mathrm{kg}),{ }^{*} p<0.05$ and ${ }^{\# \#} P<0.01$ compared to the sham group; ${ }^{*} P<0.05$ and ${ }^{* *} P<0.01$ compared to the OVX group. 
of MC3T3-E1 cells. Low concentrations of curcumin (1$10 \mu \mathrm{M})$ could reverse the oxidative damage, but a high concentration $(20 \mu \mathrm{M})$ failed. Furthermore, the NF- $\kappa B$ and MAPK signaling pathways might be part of the potential mechanism involved in this protective process. In addition, curcumin reversed the ratio of oxidants and antioxidants, it improved the micro-architecture of the trabecular bone in an animal model of oxidative damage, and the effect is in a dose-dependent manner (Figure 9). Curcumin might therefore be a substantial alternative for prevention oxidative stress during material implanted, facilitating the bony fusion of artificial implanted devices.

\section{MATERIALS AND METHODS}

\section{Chemicals and reagents}

Curcumin (molecular weight, 368.38; purity, 98.0\%; dissolved in distilled water with DMSO) was purchased from Sigma-Aldrich (St. Louis, MO, USA). The BCIP/ NBT alkaline phosphatase color development kit and the GSH and MDA assay kits were obtained from the Beyotime Institute of Biotechnology (Shanghai, China). The Prime Script RT reagent kit and SYBR Premix Ex Taq were obtained from Takara Biotechnology (Dalian, China). RANKL and IL-6 ELISA assay kits were obtained from R\&D systems Inc. (Minneapolis, MN, USA). Antibodies against p-P38, P38, p-ERK1/2, ERK1/2, $\mathrm{p}-\mathrm{JNK}, \mathrm{JNK}, \mathrm{I} \kappa \mathrm{B}-\alpha, \mathrm{p}-\mathrm{P} 65$, and $\beta$-actin were purchased from Abcam (Beverly, MA, USA).All chemicals (dexamethasone, ascorbic acid, $\beta$-glycerophosphate, $\mathrm{H}_{2} \mathrm{O}_{2}$, $\mathrm{N}$-acetyl-L-cysteine (NAC), methylthiazolyltetrazolium (MTS), Alizarin Red S, p-nitrophenylphosphate (pNPP), calcium Assay kit, and Triton X-100, 2',7'-dichlorofluorescein diacetate (DCFH-DA)) were also purchased from Sigma-Aldrich (St. Louis, MO, USA). All other reagents were of analytical grade.

\section{Cell culture and treatment}

Murine MC3T3-E1 cells were purchased from the American Type Culture Collection (ATCC, Manassas, VA, USA). Cells were cultivated in modified $\alpha$-MEM medium with 10\% heat-inactivated FBS (Gibco Invitrogen, Carlsbad, CA, USA) at $37^{\circ} \mathrm{C}$ in a humidified $5 \% \mathrm{CO}_{2}$ atmosphere. The medium was replenished every three days. $\mathrm{H}_{2} \mathrm{O}_{2}$ served as an exogenous ROS treatment, whereas $\mathrm{N}$-acetyl-L-cysteine (NAC) served as an antioxidant. Fresh osteogenic medium (OM, 0.1 $\mu \mathrm{M}$ dexamethasone, $50 \mu \mathrm{g} / \mathrm{ml}$ ascorbic acid, and $10 \mathrm{mM}$ $\beta$-glycerophosphate), containing different concentrations of curcuminwas used for osteogenic induction after $0.3 \mathrm{mM} \mathrm{H} \mathrm{H}_{2}$ was administered for $24 \mathrm{~h}$. All of the experiments were performed in duplicate wells and repeated three times.

\section{Cell viability assay}

MC3T3-E1 cells were treated with different concentrations of $\mathrm{H}_{2} \mathrm{O}_{2}(0.1,0.2,0.3,0.5,1$ and $2 \mathrm{mM})$

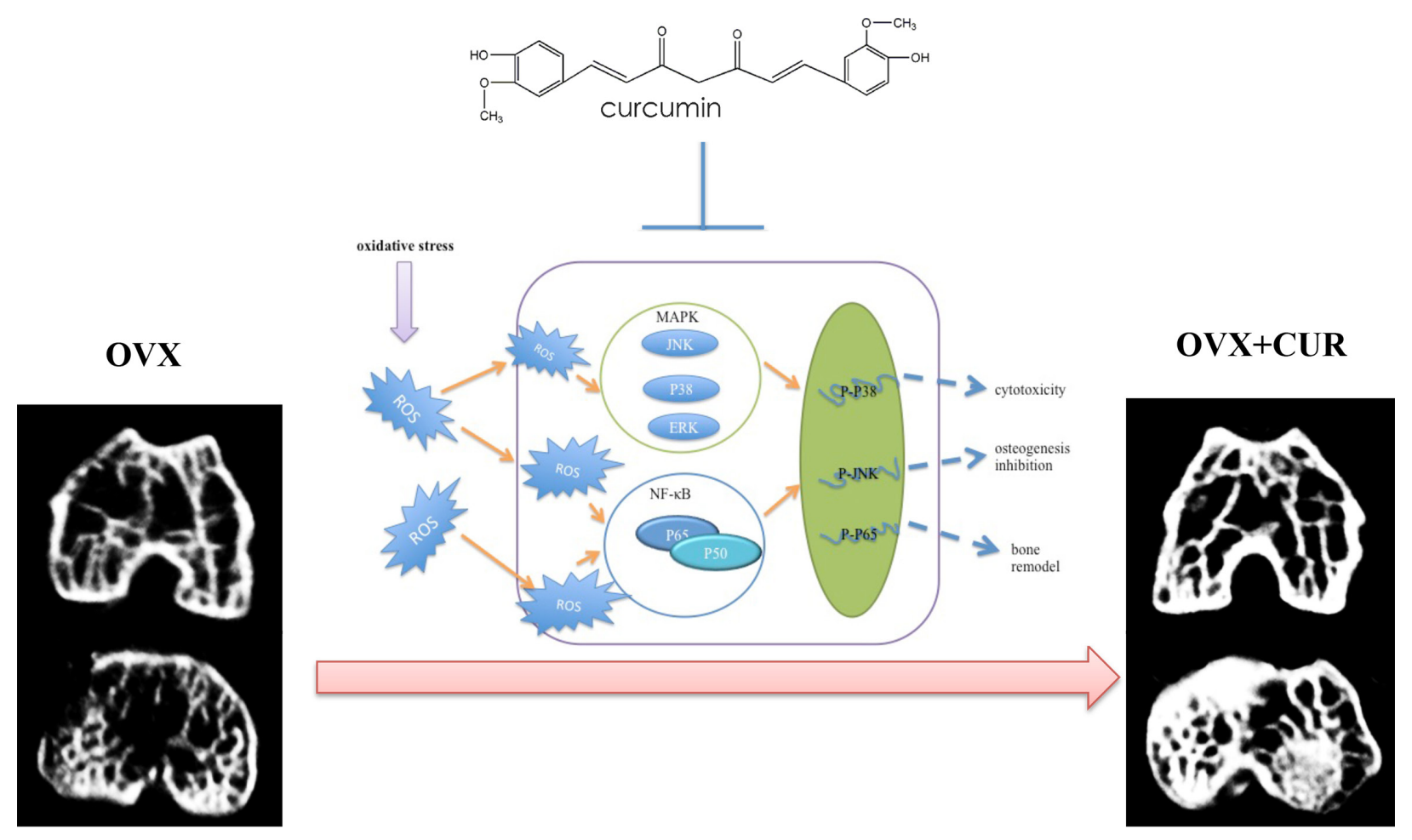

Figure 9: A schematic representation of the main conclusions of this study. 
for $24 \mathrm{~h}$ in whole culture. Different concentrations of curcumin $(1,5,10,20,50,100$ and $200 \mu \mathrm{M}$ dissolved in $0.1 \%$ Dimethyl sulfoxide (DMSO) in distilled water) were also added to the whole cultures. A control group was treated with $0.1 \%$ DMSO in distilled water. The cells were incubated using whole culture medium, which contained curcumin $(1,5,10,20,50,100$ or $200 \mu \mathrm{M})$ for $24 \mathrm{~h}$ followed by the administration of $300 \mu \mathrm{M} \mathrm{H}_{2} \mathrm{O}_{2}$ for $24 \mathrm{~h}$. The cells were rinsed with PBS once, and then, 120 $\mu \mathrm{l}$ of fresh medium containing $20 \mu \mathrm{l}$ MTS was added to all wells. After incubation at $37^{\circ} \mathrm{C}$ for $3 \mathrm{~h}$, the absorbance at $490 \mathrm{~nm}$ was measured using a spectrophotometric plate reader.

\section{Alkaline phosphatase (ALP) staining and activity assay}

The murine MC3T3-E1 cells were incubated in 96-well or 6-well plates overnight and treated with different concentrations of $\mathrm{H}_{2} \mathrm{O}_{2}$ for $24 \mathrm{~h}$, and/or the different concentrations of curcumin in osteogenic media throughout the differentiation process. After osteogenic induction for 7 days, the cells were lysed with $1 \%$ Triton $\mathrm{X}-100$ overnight at $4^{\circ} \mathrm{C}$. A portion of the cell lysate was incubated with p-NPP in a buffer $(0.1 \mathrm{M}$ glycine, 1 $\mathrm{mMMgCl}_{2}$, and $\mathrm{ZnCl}_{2}, \mathrm{pH} 10.3$ ) at $37^{\circ} \mathrm{C}$ for $30 \mathrm{~min}$; the reaction was terminated by adding $2 \mathrm{M} \mathrm{NaOH}$, and the absorbance was measured at $405 \mathrm{~nm}$. The ALP activity was normalized to total protein, which was measured using the Bradford protein assay. The cells were stained using the BCIP/NBT alkaline phosphatase color development kit according to the manufacturer's instructions. The assay was performed 7 days after osteogenesis.

\section{Alizarin red staining and calcium accumulation assay}

The mineralization of MC3T3-E1 cells was measured using Alizarin Red staining. The cells were incubated with osteogenic medium containing different concentrations of curcumin for 21 days after exposure to $\mathrm{H}_{2} \mathrm{O}_{2}$ for $24 \mathrm{~h}$. For Alizarin Red staining, cells were fixed with $4 \%$ paraformaldehyde for $15 \mathrm{~min}$. The cells were stained with $40 \mathrm{mM}$ Alizarin Red S for $15 \mathrm{~min}$ at room temperature. After rinsing with distilled water to completely remove the unbound stain, the cells were visualized and imaged using a light microscope (Nikon, Eclipse TS100, Japan) and digital camera (Nikon, D330, Japan). The calcium content was measured using a Calcium Assay kit at 21days according to the manufacturer's instructions. Briefly, samples were supplemented with $1 \mathrm{M}$ acetic acid and placed on a vortex overnight at $4^{\circ} \mathrm{C}$ to extract the calcium from the mineralized matrix. In a 96-well clear polycarbonate plate, a portion of this cell extract was mixed with 150 $\mu \mathrm{L}$ Calcium Assay reagent and incubated for $30 \mathrm{~s}$ at room temperature. The absorbance at $575 \mathrm{~nm}$ was determined using a SpectraMAX 250 microplate reader. The samples were measured in triplicate and compared to a calcium calibration curve. The calcium content was normalized to cell protein levels and expressed as relative calcium content normalized to a control sample.

\section{RNA isolation, cDNA synthesis and qRT-PCR.}

Total RNA was extracted with TRIzol reagent (Invitrogen, CA, USA) according to the manufacturer's instructions. Total RNA (500 ng of mRNA) from each sample was subjected to reverse transcription using a commercially available kit according to the manufacturer's protocol (TaKaRa, Japan). The primers used to amplify the osteogenic genes are listed in Table 1. All experiments were performed using a real-time PCR system (CFX ConnectTM Real-time system, Bio-Rad, USA). The expression levels of each mRNA were normalized to that of GAPDH. The relative expression levels of all genes were calculated using the $2^{-\Delta \Delta \mathrm{Ct}}$ method.

\section{RANKL and IL-6 measurements}

After exposure to $\mathrm{H}_{2} \mathrm{O}_{2}$ for $24 \mathrm{~h}$, the murine MC3T3-E1 cells were incubated using whole culture medium, which contained different concentrations (1, 10, and $20 \mu \mathrm{M}$ ) of curcumin for 7 days. The production of RANKL and IL- 6 in culture medium was tested using a sandwich ELISA assay kit according to the manufacturer's instructions. The total protein concentrations were measured using the Bradford protein assay method.

\section{Intracellular ROS level determination}

Intracellular ROS levels were evaluated using a method previously described with slight modification [53]. Cells were seeded in 6-well plates at $2 \times 10^{5}$ cells/well. After culturing for $24 \mathrm{~h}$ in the incubator, different doses of $\mathrm{H}_{2} \mathrm{O}_{2}$ were added. In brief, after the cells were exposed to $\mathrm{H}_{2} \mathrm{O}_{2}$ for $1 \mathrm{~h}$ or $24 \mathrm{~h}$, the cells were incubated in growth medium containing $20 \mu \mathrm{M}$ DCFH-DA for $30 \mathrm{~min}$ at $37^{\circ} \mathrm{C}$. The cells were then rinsed with $\mathrm{PBS}$ to remove the residual extracellular DCFH-DA. The cellular fluorescence was visualized using fluorescence microscopy (Axio Observer Z1, Carl ZeissInc.), or the cells were detached with trypsin and re-suspended after centrifugation. The fluorescence levels of the samples were measured using flow cytometry with the excitation and emission wavelengths set at 488 and $525 \mathrm{~nm}$, respectively.

\section{Preparation of cell lysates and western blot}

Cells were harvested, and protein was extracted using RIPA buffer supplemented with a protease inhibitor 
cocktail (Sigma-Aldrich). The total protein concentration was determined with a BCA protein assay kit according to the manufacturer's instructions (Thermo Fisher Scientific, Rockford, IL, USA). Thirty micrograms of protein was separated by SDS-PAGE and then transferred onto a 0.45 $\mu \mathrm{m}$ PVDF membrane (Immobilon TM, Millipore Corp., Bedford, MA). The membranes were blocked and then probed overnight with rabbit polyclonal antibodies against p-p65, p-IкB $\alpha$, p-JNK, JNK, p-P38, P38, p-ERK1/2, ERK1/2and $\beta$-actin. The antibodies were detected using enhanced chemiluminescence with HRP-conjugated secondary antibodies (Jackson Immuno Research). The values of the band intensities were quantified using Image J software.

\section{Animals and curcumin intervention}

The usage of animals were approved by the Institutional Animal Care and Use Committee at the University of Sun Yat-sen(permission code: SYXK20100108). Forty 8 weeksold, BALB/c female mice, weighing about $20.52 \pm 1.27 \mathrm{~g}$, were obtained from the experimental animal center of the first affiliated hospital of Sun Yat-sen university (Guangzhou, China). There were no significant differences in the initial body weights of the mice among all 4 groups in the experiment. The mice were allowed to adapt to the laboratory environment (a well-ventilated controlled room maintained at $20^{\circ} \mathrm{C}$ on a $12 \mathrm{~h} \mathrm{light/dark}$ cycle; the animals were given free access to water and food) for 7 days before the surgery. Subsequently, the mice underwent sham operation ( $n=10)$ or ovariectomy (OVX) $(n=30)$ under anesthesia using sodium pentobarbital (50 $\mathrm{mg} / \mathrm{kg}$ body weight, i.p.). The ovariectomy operation was performed with a dorsal approach. A total of $30 \mathrm{BALB} / \mathrm{c}$ female mice were randomly divided into three groups: 1) an OVX group, with DMSO solvent administered intraperitoneally $(n=10) ; 2)$ an OVX group, with curcumin solution administered intraperitoneally $(5 \mu \mathrm{mol} /$ $\mathrm{kg}$ body weight; $n=10$ ) daily; and 3 ) an OVX group, with curcumin solution administered intraperitoneally $(15 \mu \mathrm{mol} /$ $\mathrm{kg}$ body weight; $n=10$ ) daily. Curcumin was dissolved in distilled water with DMSO. One week after the operation, the treatments were initiated and continued for 12 weeks. Blood samples were obtained from the hearts of the anesthetized mice, and serum samples were prepared by centrifugation. The femurs of the mice were collected for further analysis, and the adherent tissue was discarded.

\section{Measurements of serum malondialdehyde (MDA) andglutathione (GSH)}

The MDA activity of the whole blood samples was determined using an MDA assay kit according to the manufacturer's instructions. Thiobarbituric acid binding to malondialdehyde, formed during lipid peroxidation, results in a chromogenic complex. In a spectrophotometer, the change in absorption peak was detected at $532 \mathrm{~nm}$. Colorimetry was used to detect the malondialdehyde activity level in whole blood samples. Additionally, the activity of GSH was determined using a GSH assay kit. The GSH activity was determined by the reaction of GSH with dithio-bis-nitrobenzoic acid(DTNB) to produce a product that could be measured using a spectrophotometer at $412 \mathrm{~nm}$.

\section{Assessment of bone micro-architecture and bone mass by micro-computed tomography}

The distal femurs were scanned using Inveon microCT/PET (Siemens Medical Solutions, Germany) with $15 \mu \mathrm{m}$ resolution, $80 \mathrm{kV}$ tube voltage and $500 \mu \mathrm{A}$ tube current. The reconstruction and $3 \mathrm{D}$ quantitative analyses were determined using Inveon research workplace 4.1 software. Similar settings for scans and analyses were used for all of the samples. In the femur, the scanning regions were confined to the distal metaphysis, extending proximally $5.0 \mathrm{~mm}$ from the distal tip of the femoral condyle. The following 3D indices in the defined region of interest (ROI) were analyzed: bone mineral density (BMD), bone surface/total volume (BS/TV), trabecular number (Tb.N), trabecular thickness (Tb.Th), trabecular separation (Tb.Sp), trabecular bone pattern factor (Tb.Pf) and relative bone volume/total volume (BV/TV,\%). The operator who conducted the scan analysis was blinded to the procedure associated with the specimens.

\section{Histological examination by Van Gieson (VG) staining}

The femurs from all mice was collected and fixed in $4 \%$ paraformaldehyde for $48 \mathrm{~h}$. After dehydration and embedding, the distal femurs were embedded in paraffin. The sections were cut and stained with VG staining, which was used to stain for collagen fibers according to the manufacturer's instructions, and examined by light microscopy.

\section{Statistical analysis}

The data are presented as the means \pm SD. The differences between two groups were probed using the Student's $t$-test. The differences among multiple groups were evaluated using a one-way ANOVA. Statistically significant results were indicated as ${ }^{*} P<0.05,{ }^{* *} P<0.01$, ${ }^{\#} P<0.05$, and ${ }^{\# \#} P<0.01$. Each experiment was repeated independently at least three times.

\section{Abbreviations}

$\mathrm{H}_{2} \mathrm{O}_{2}$ : hydrogen peroxide; BMD: bone mineral density; MSCs: mesenchymal stem cells; ROS: reactive oxygen species. 


\section{Author contributions}

X.Z. Geoff R and Z.Z. conceived the idea. Q.Q., L.L. and X.Z. designed the experiments. Q.Q., L.L.and Y.C. conducted the experiments. Q.Q., L.L. and Z.L. analysed the results. Q.Q. and L.L.wrote the manuscript. X.Z. supervised and supported the study. All authors reviewed the manuscript.

\section{ACKNOWLEDGMENTS}

None.

\section{CONFLICTS OF INTEREST}

The authors declare that they have no conflicts of interest to disclose.

\section{GRANT SUPPORT}

This work was supported by the National Natural Science Foundation of China (No. 31430030, U1601220), The Jiangxi province Science and Technology Support Program (No. 20151BBG70119).

\section{REFERENCES}

1. Irmola TM, Hakkinen A, Jarvenpaa S, Marttinen I, Vihtonen K, Neva M. Reoperation Rates Following Instrumented Lumbar Spine Fusion. Spine. 1976; 2017;13.

2. Rajaee SS, Bae HW, Kanim LE, Delamarter RB. Spinal fusion in the United States: analysis of trends from 1998 to 2008. Spine. 1976; 2012; 37:67-76.

3. Zou X, Li H, Egund N, Lind M, Bunger C. Inhibition of spinal fusion by use of a tissue ingrowth inhibitor. Eur Spine J. 2004; 13:157-163.

4. Zou X, Li H, Zou L, Mygind T, Lind M, Bunger C. Porous tantalum trabecular metal scaffolds in combination with a novel marrow processing technique to replace autograft. Adv Exp Med Biol. 2006; 585:197-208.

5. Zou X, Zou L, Foldager C, Bendtsen M, Feng W, Bunger CE. Different mechanisms of spinal fusion using equine bone protein extract, rhBMP-2 and autograft during the process of anterior lumbar interbody fusion. Biomaterials. 2009; 30:991-1004.

6. Foldager C, Bendtsen M, Nygaard JV, Zou X, Bunger C. Differences in early osteogenesis and bone microarchitecture in anterior lumbar interbody fusion with rhBMP-2, equine bone protein extract, and autograft. Bone. 2009; 45:267-73.

7. Sanchez-Rodriguez MA, Ruiz-Ramos M, Correa-Munoz E, Mendoza-Nunez VM. Oxidative stress as a risk factor for osteoporosis in elderly Mexicans as characterized by antioxidant enzymes. BMC Musculoskelet Disord. 2007; 8:124.
8. Atashi F, Modarressi A, Pepper MS. The role of reactive oxygen species in mesenchymal stem cell adipogenic and osteogenic differentiation: a review. Stem Cells Dev. 2015; 24:1150-1163.

9. Tsay J, Yang Z, Ross FP, Cunningham-Rundles S, Lin H, Coleman R, Mayer-Kuckuk P, Doty SB, Grady RW, Giardina PJ, Boskey AL, Vogiatzi MG. Bone loss caused by iron overload in a murine model: importance of oxidative stress. Blood. 2010; 116:2582-2589.

10. Manolagas SC. From estrogen-centric to aging and oxidative stress: a revised perspective of the pathogenesis of osteoporosis. Endocr Rev. 2010; 31:266-300.

11. Li J, Wang Q, Yang R, Zhang J, Li X, Zhou X, Miao D. BMI-1 Mediates Estrogen-Deficiency-Induced Bone Loss by Inhibiting Reactive Oxygen Species Accumulation and T Cell Activation. J Bone Miner Res. 2017; 32:962-973.

12. Bimonte S, Barbieri A, Leongito M, Piccirillo M, Giudice A, Pivonello C, de Angelis C, Granata V, Palaia R, Izzo F. Curcumin AntiCancer Studies in Pancreatic Cancer. Nutrients. 2016; 8:433.

13. Daniel S, Limson JL, Dairam A, Watkins GM, Daya S. Through metal binding, curcumin protects against leadand cadmium-induced lipid peroxidation in rat brain homogenates and against lead-induced tissue damage in rat brain. J Inorg Biochem. 2004; 98:266-275.

14. Kunnumakkara AB, Bordoloi D, Padmavathi G, Monisha J, Roy NK, Prasad S, Aggarwal BB. Curcumin, the golden nutraceutical: multitargeting for multiple chronic diseases. Br J Pharmacol. 2017; 174:1325-1348.

15. Ng QX, Koh SSH, Chan HW, Ho CYX. Clinical Use of Curcumin in Depression: A Meta-Analysis. J Am Med Dir Assoc. 2017; 18:503-508.

16. Tzankova V, Gorinova C, Kondeva-Burdina M, Simeonova R, Philipov S, Konstantinov S, Petrov P, Galabov D, Yoncheva K. In vitro and in vivo toxicity evaluation of cationic PDMAEMA-PCL-PDMAEMA micelles as a carrier of curcumin. Food Chem Toxicol. 2016; 97:1-10.

17. Wu J, Pan X, Fu H, Zheng Y, Dai Y, Yin Y, Chen Q, Hao Q, Bao D, Hou D. Effect of curcumin on glycerol-induced acute kidney injury in rats. Sci Rep. 2017; 7:10114.

18. Prasad S, Gupta SC, Tyagi AK, Aggarwal BB. Curcumin, a component of golden spice: from bedside to bench and back. Biotechnol Adv. 2014; 32:1053-1064.

19. Lim GP, Chu T, Yang F, Beech W, Frautschy SA, Cole GM. The curry spice curcumin reduces oxidative damage and amyloid pathology in an Alzheimer transgenic mouse. J Neurosci. 2001; 21:8370-8377.

20. Arulselvan P, Fard MT, Tan WS, Gothai S, Fakurazi S, Norhaizan ME, Kumar SS. Role of Antioxidants and Natural Products in Inflammation. Oxid Med Cell Longev. 2016; 2016:5276130.

21. Selvam S, Kundu K, Templeman KL, Murthy N, García AJ. Minimally invasive, longitudinal monitoring of biomaterial- 
associated inflammation by fluorescence imaging. biomaterials. 2011; 31:7785-7792.

22. Kim MS, Ahn HH, Shin YN, Cho MH, Khang G, Lee HB. An in vivo study of the host tissue response to subcutaneous implantation of PLGA- and/or porcine small intestinal submucosa-based scaffolds. Biomaterials. 2007; 28:5137-5143.

23. Baek KH, Oh KW, Lee WY, Lee SS, Kim MK, Kwon HS, Rhee EJ, Han JH, Song KH, Cha BY, Lee KW, Kang MI. Association of oxidative stress with postmenopausal osteoporosis and the effects of hydrogen peroxide on osteoclast formation in human bone marrow cell cultures. Calcif Tissue Int. 2010; 87:226-2235.

24. Zhang JK, Yang L, Meng GL, Yuan Z, Fan J, Li D, Chen JZ, Shi TY, Hu HM, Wei BY, Luo ZJ, Liu J. Protection by salidroside against bone loss via inhibition of oxidative stress and bone-resorbing mediators. PLoS One. 2013; 8:e57251.

25. Huang Q, Gao B, Jie Q, Wei BY, Fan J, Zhang HY, Zhang JK, Li XJ, Shi J, Luo ZJ, Yang L, Liu J. Ginsenoside$\mathrm{Rb} 2$ displays anti-osteoporosis effects through reducing oxidative damage and bone-resorbing cytokines during osteogenesis. Bone. 2014; 66:306-314.

26. Li L, Qi Q, Luo J, Huang S, Ling Z, Gao M, Zhou Z, Stiehler M, Zou X. FOXO1-suppressed miR-424 regulates the proliferation and osteogenic differentiation of MSCs by targeting FGF2 under oxidative stress. Sci Rep. 2017; $7: 42331$

27. Liu J, Zhu P, Song P, Xiong W, Chen H, Peng W, Wang S, Li S, Fu Z, Wang Y, Wang H. Pretreatment of Adipose Derived Stem Cells with Curcumin Facilitates Myocardial Recovery via Antiapoptosis and Angiogenesis. Stem Cells Int. 2015; 2015:638153.

28. Geng S, Wang S, Zhu W, Xie C, Li X, Wu J, Zhu J, Jiang Y, Yang X, Li Y, Chen Y, Wang X, Meng Y, et al. Curcumin attenuates BPA-induced insulin resistance in HepG2 cells through suppression of JNK/p38 pathways. Toxicol Lett. $2017 ; 272: 75-83$.

29. Arai M, Shibata Y, Pugdee K, Abiko Y, Ogata Y. Effects of reactive oxygen species (ROS) on antioxidant system and osteoblastic differentiation in MC3T3-E1 cells. IUBMB Life. 2007; 59:27-33.

30. Mody N, Parhami F, Sarafian TA, Demer LL. Oxidative stress modulates osteoblastic differentiation of vascular and bone cells. Free Radic Biol Med. 2001; 31:509-519.

31. Bai XC, Lu D, Liu AL, Zhang ZM, Li XM, Zou ZP, Zeng WS, Cheng BL, Luo SQ. Reactive oxygen species stimulates receptor activator of NF-kappaB ligand expression in osteoblast. J Biol Chem. 2005; 280:17497-506.

32. Liu AL, Zhang ZM, Zhu BF, Liao ZH, Liu Z. Metallothionein protects bone marrow stromal cells against hydrogen peroxide-induced inhibition of osteoblastic differentiation. Cell Biol Int. 2004; 28:905-911.

33. Wang N, Wang F, Gao Y, Yin P, Pan C, Liu W, Zhou Z, Wang J. Curcumin protects human adipose-derived mesenchymal stem cells against oxidative stress-induced inhibition of osteogenesis. J Pharmacol Sci. 2016; 132:192-200.

34. Sullivan CB, Porter RM, Evans CH, Ritter T, Shaw G, Barry F, Murphy JM. TNFalpha and IL-1beta influence the differentiation and migration of murine MSCs independently of the NF-kappaB pathway. Stem Cell Res Ther. 2014; 5:104.

35. Girasole G, Jilka RL, Passeri G, Boswell S, Boder G, Williams DC, Manolagas SC. 17 beta-estradiol inhibits interleukin-6 production by bone marrow-derived stromal cells and osteoblasts in vitro: a potential mechanism for the antiosteoporotic effect of estrogens. J Clin Invest. 1992; 89:883-891.

36. Mohankumar K, Sridharan S, Pajaniradje S, Singh VK, Ronsard L, Banerjea AC, Somasundaram DB, Coumar MS, Periyasamy L, Rajagopalan R. BDMC-A, an analog of curcumin, inhibits markers of invasion, angiogenesis, and metastasis in breast cancer cells via NF-kappaB pathway--A comparative study with curcumin. Biomed Pharmacother. 2015; 74:178-186.

37. Kao NJ, Hu JY, Wu CS, Kong ZL. Curcumin represses the activity of inhibitor-kappaB kinase in dextran sulfate sodium-induced colitis by S-nitrosylation. Int Immunopharmacol. 2016; 38:1-7.

38. Bharti AC, Donato N, Singh S, Aggarwal BB. Curcumin (diferuloylmethane) down-regulates the constitutive activation of nuclear factor-kappa B and IkappaBalpha kinase in human multiple myeloma cells, leading to suppression of proliferation and induction of apoptosis. Blood. 2003; 101:1053-1062.

39. Gao P, Wang XM, Qian DH, Qin ZX, Jin J, Xu Q, Yuan QY, Li XJ, Si LY. Induction of oxidative stress by oxidized LDL via meprinalpha-activated epidermal growth factor receptor in macrophages. Cardiovasc Res. 2013; 97:533-543.

40. Liang SJ, Zeng DY, Mai XY, Shang JY, Wu QQ, Yuan JN, Yu BX, Zhou P, Zhang FR, Liu YY, Lv XF, Liu J, Ou JS, et al. Inhibition of Orai1 Store-Operated Calcium Channel Prevents Foam Cell Formation and Atherosclerosis. Arterioscler Thromb Vasc Biol. 2016; 36:618-628.

41. Cao J, Ye B, Lin L, Tian L, Yang H, Wang C, Huang W, Huang Z. Curcumin Alleviates oxLDL Induced MMP9 and EMMPRIN Expression through the Inhibition of NF-kappaB and MAPK Pathways in Macrophages. Front Pharmacol. 2017; 8:62.

42. Soetikno V, Sari FR, Sukumaran V, Lakshmanan AP, Mito S, Harima M, Thandavarayan RA, Suzuki K, Nagata M, Takagi R, Watanabe K. Curcumin prevents diabetic cardiomyopathy in streptozotocin-induced diabetic rats: possible involvement of PKC-MAPK signaling pathway. Eur J Pharm Sci. 2012; 47:604-614.

43. Kalyanaraman H, Ramdani G, Joshua J, Schall N, Boss GR, Cory E, Sah RL, Casteel DE, Pilz RB. A Novel, Direct NO Donor Regulates Osteoblast and Osteoclast Functions and Increases Bone Mass in Ovariectomized Mice. J Bone Miner Res. 2017; 32:46-59. 
44. Liao L, Su X, Yang X, Hu C, Li B, Lv Y, Shuai Y, Jing H, Deng Z, Jin Y. TNF-alpha Inhibits FoxO1 by Upregulating miR-705 to Aggravate Oxidative Damage in Bone MarrowDerived Mesenchymal Stem Cells during Osteoporosis. Stem Cells. 2016; 34:1054-1067.

45. Ozgocmen S, Kaya H, Fadillioglu E, Aydogan R, Yilmaz Z. Role of antioxidant systems, lipid peroxidation, and nitric oxide in postmenopausal osteoporosis. Mol Cell Biochem. 2007; 295:45-52.

46. Sendur OF, Turan Y, Tastaban E, Serter M. Antioxidant status in patients with osteoporosis: a controlled study. Joint Bone Spine. 2009; 76:514-518.

47. Cakatay U, Aydin S, Yanar K, Uzun H. Gender-dependent variations in systemic biomarkers of oxidative protein, DNA, and lipid damage in aged rats. Aging Male. 2010; 13:51-58.

48. Kinov P, Leithner A, Radl R, Bodo K, Khoschsorur GA, Schauenstein K, Windhager R. Role of free radicals in aseptic loosening of hip arthroplasty. J Orthop Res. 2006; 24:55-62.

49. Chen X, Zhi X, Pan P, Cui J, Cao L, Weng W, Zhou Q, Wang L, Zhai X, Zhao Q, Hu H, Huang B, Su J. Matrine prevents bone loss in ovariectomized mice by inhibiting RANKLinduced osteoclastogenesis. Faseb j. 2017; 31:4855-4865.

50. Fischer V, Haffner-Luntzer M, Prystaz K, Scheidt AV, Busse B, Schinke T, Amling M, Ignatius A. Calcium and vitamin-D deficiency marginally impairs fracture healing but aggravates posttraumatic bone loss in osteoporotic mice. Sci Rep. 2017; 7:7223.

51. Lopez-Herradon A, Fujikawa R, Gomez-Marin M, StedileLovatel JP, Mulero F, Ardura JA, Ruiz P, Munoz I, Esbrit P, Mahillo-Fernandez I, Ortega-de Mues A. Impact of Chiropractic Manipulation on Bone and Skeletal Muscle of Ovariectomized Rats. Calcif Tissue Int. 2017; 101:519-529.

52. Chainani-Wu N. Safety and anti-inflammatory activity of curcumin: a component of tumeric (Curcuma longa). J Altern Complement Med. 2003; 9:161-168.

53. Tang Y, Vater C, Jacobi A, Liebers C, Zou X, Stiehler M. Salidroside exerts angiogenic and cytoprotective effects on human bone marrow-derived endothelial progenitor cells via $\mathrm{Akt} / \mathrm{mTOR} / \mathrm{p} 70 \mathrm{~S} 6 \mathrm{~K}$ and MAPK signalling pathways. Br J Pharmacol. 2014; 171:2440-2456. 